Article

\title{
Experimental Investigations on the Effects of Rotational Speed on Temperature and Microstructure Variations in Incremental Forming of T6- Tempered and Annealed AA2219 Aerospace Alloy
}

\author{
Asim Ahmad Riaz ${ }^{1, *}$, Naveed Ullah ${ }^{1}$, Ghulam Hussain ${ }^{2, *}$, Mohammed Alkahtani ${ }^{3,4, *}$, \\ Muhammad Naeem Khan ${ }^{1}$ and Shaukat Khan ${ }^{2}$ \\ 1 Department of Mechanical Engineering, University of Engineering \& Technology, Peshawar 25000, Pakistan; \\ naveedullah@uetpeshawar.edu.pk (N.U.); naeem1962@yahoo.com (M.N.K.) \\ 2 Faculty of Mechanical Engineering, GIK Institute of Engineering Sciences \& Technology, Swabi 23640, Pakistan; \\ shaukatkhan1512@gmail.com \\ 3 Industrial Engineering Department, College of Engineering, King Saud University, Riyadh 11421, Saudi Arabia \\ 4 Raytheon Chair for Systems Engineering (RCSE chair), Advanced Manufacturing Institute, \\ King Saud University, Riyadh 11421, Saudi Arabia \\ * Correspondence: engr.asim@uetpeshawar.edu.pk (A.A.R.); ghulam.hussain@giki.edu.pk (G.H.); \\ moalkahtani@ksu.edu.sa (M.A.)
}

Received: 15 May 2020; Accepted: 15 June 2020; Published: 17 June 2020

\begin{abstract}
This research work primarily focused on investigating the effects of changing rotational speed on the forming temperature and microstructure during incremental sheet metal forming (ISF) of AA-2219-O and AA-2219-T6 sheets. Tool rotational speed was varied in the defined range (50-3000 rpm). The tool feed rate of $3000 \mathrm{~mm} / \mathrm{min}$ and step size of $0.3 \mathrm{~mm}$ with spiral tool path were kept fixed in the tests. The sheets were formed into pyramid shapes of $45^{\circ}$ draw angle, with the hemispherical end forming tool of $12 \mathrm{~mm}$ diameter. While the sheets were forming, the temperature variation due to friction at the sheet-tool contact zone was recorded, using a non-contact laser projected infrared temperature sensor. It was observed that the temperature rising rate for the T6 sheet during ISF is higher as compared to the annealed sheet, thereby showing that the T6 tempered sheet offers higher friction than the annealed sheet. Due to this reason, the T6 tempered sheet fails to achieve the defined forming depth of $25 \mathrm{~mm}$ when the rotational speed exceeds $2000 \mathrm{rpm}$. The effects of rotational speed and associated rise in the temperature were examined on the microstructure, using the scanning electron microscopic (SEM). The results reveal that the density of second phase particles reduces with increasing speed reasoning to corresponding temperature rise. However, the particle size in both tempers of AA2219 received a slight change and showed a trivial response to an increase in the rotational speed.
\end{abstract}

Keywords: incremental sheet metal forming; formability; temperature profile; AA-2219; microstructure

\section{Introduction}

In major industries such as aerospace and automobile, conventional sheet forming methods are used to fabricate a variety of geometries and components. Various conventional methods are currently in use, including spinning, flow forming and shear forming. Spinning is one of the sheet-forming methods which involves forming a flat sheet into symmetric geometries, using a flat sheet as a starting blank [1-3]. Flow forming produces tubular parts through significant reduction in the thickness of a 
ring-shaped starting blank. Shear forming also relies on substantial thickness reduction of starting blank but produces conical and profiled components [4,5].

The acceptance and deployment of these techniques declines when it comes to the requirement of expensive dies for different part geometries, as well as its low flexibility. A Paradigm shift in the demand of customized and special components is also threatening the conventional forming methods in terms of cost and flexibility. This technique is no longer cost-effective and sustainable for prototypes and small production runs. Consequently, this requires a novel technique which has the potential and capability to produce symmetric and asymmetric parts at a low cost. The ISF method offers cost-effective and dieless forming to produce parts for small batches, as well as for prototypes. In addition, due to localized deformation, the process maximizes the formability of sheets, thereby allowing the forming of complicated shapes [6]. Due to its potential forming attributes, this method is gaining the attention of manufacturers in major industries. This method is dominantly and successfully in use in automobile [7,8], aerospace and biomedical sectors [9-12]. Like other techniques used, ISF also has certain demerits that include geometrical accuracy, springback, lead-time and mechanical properties [13]. Several studies have been conducted to analyze the optimum process parameters and part accuracy, as well as to highlight the combination of process parameters that leads to the unfavorable results.

The setup requirements for ISF process make it more attractive and user friendly. Additionally, 3-axis CNC milling machine tool, a sheet blankholder, hemispherical/flat form tool and CAD/CAM software makes the process more viable. The process overview consists of a hemispherical/flat tool chucked in the machine tool spindle; tool moves with continuous sheet stretching at the tool-blank contact. The tool moves from the periphery to the center, according to the predefined spiral trajectory, using CAD/CAM software, which forms the sheet into the desired part. The tool continuously moves down, in small vertical increments, to the required forming depth, via a series of spiral passes. The selection of the other process parameters, i.e., feed rate, incremental vertical steps, spindle speed and forming angles, is user-defined [14,15].

This method is not only dedicated to metal sheet but can be used for other material classes. Alloys, including aluminum [16,17], magnesium [18] and titanium alloys [19,20], as well as polymers [21,22], can be processed for parts and components by using ISF. From the last decade, aluminum has remained the most research-oriented material because of its extensive use and applications in major industries due to its friendly and flexible properties. Aluminum alloys of the 5XXX series are used in automobile due to its high strength to weight ratios [23]. In ISF, aluminum alloy sheets of different series show failure when processed under different process parameters. In this study, the sheet was heat treated, and its forming behavior was investigated and compared under varying tool rotational speeds.

Heat treatment routes for Al-2219 alloy have been investigated by S. Khan et al. [24], resulting in best formability and acceptable geometrical accuracy during incremental sheet forming at zero tool rotational speed. Three different heat-treatment routes were selected (annealed AA-2219 (A)-solution treated (ST)-Age hardening (AH)-ISF) and shuffled accordingly, to investigate for the best heat-treatment path that gives the best results during forming. He concluded that the A-ST-ISF-AH route provides the best results in comparison. The material processed through the A-ST-AH-ISF route shows geometrical inaccuracies and low formability and endures the maximum residual stresses. Research has already been conducted to highlight the effect of the tailoring of material properties, selecting different heat-treated sheets can improve the geometrical accuracy and formability [25]. Kesnar et al. studied how the prolonged precipitation treatments and homogenization of AA-2024 alloys improve ductility, with an effect on material strength [26]. Totik et al. also studied the AA-2014 alloys for the same condition as Kesnar and found that second-phase particles are formed and density increases in as-cast ingots, as compared to homogenized ingots. In addition, cooling rate affects the density of phases, and the shifting of the second phase precipitates from grain boundaries into grains decreases strength, while enhancing ductility [27]. Mohammadi et al. studied the formability of aluminum alloy AA-2024 in different heat-treatment conditions, i.e., AA2024-O-temper (annealed), AA2024-W-temper (solution 
treated-quenched) and AA2024-T-Temper (solution heat treated-quenched, followed by cold work). They found that, for O-temper and $\mathrm{W}$-temper, the formability is increased by $41 \%$ and $32 \%$, respectively, in comparison with T-Temper. In addition, special setup and additional expenses are required for laser-assisted heating of T-Temper sheets at $360^{\circ} \mathrm{C}$, to improve formability. [28]. Wang et al. studied the AA2024 and progressive increase in the ductility with temperature is observed that ductility increases with temperature to $450^{\circ} \mathrm{C}$ and resultant formability increases due to the reduction in flow stresses, but conversely it effects the material properties due to microstructural variation at elevated temperature [29].

During high-speed incremental forming, metal sheet experiences substantial improvement in formability. The reason for improvement in formability at high tool speed is that sliding friction forces reduce and heat generation increases at the contact zone between tool and sheet. The maximum temperature rise during forming of sheet metal AA3003-O at high spindle speed (2500 rpm) was estimated up to $150^{\circ} \mathrm{C}$, at optimized condition, which results in maximum formability. [30]

Aluminum alloys result in low formability when it is subjected to ISF at room temperature. However, it can be increased with the rises in temperature [31]. Various strategies were adopted to enhance the formability limits of the sheet metal. Some researchers suggest the multi-pass forming techniques [32], while others discuss the tool paths [33] and tool sizes [17]. Among the research studies, one of the methods to increase formability is to increase the temperature at the tool tip-blank interface, which can be done either by using external source or adopting frictional mean for heat generation [34]. Laser-based heating [35], electric hot incremental forming [36] and heating pads are the external methods and require additional equipment setups and process modification. On the other hand, friction stir incremental forming techniques form the alloy sheets without using an external heat element. In this technique, heat is generated as the tool rotational rate increases beyond the threshold value; formability also increases due to dynamic recrystallization $[37,38]$.

Effect of the form-tool speed and frictional heating on formability of aluminum alloys were also investigated by researchers. The formability was investigated for tool speed (2000-10000) rpm by Otsu et al., who concluded that formability of AA5052-H34 substantially increases for the tool speed exceeding $7000 \mathrm{rpm}$ [39]. Ham and Jeswiet reported an increase in formability for the cone-shaped AA3003-O due to friction heating for the tool speed of 100 and $600 \mathrm{rpm}$ [40]. Buffa et al. found an experimental conclusion by developing conical frusta of AA6082-T6 at the varying tool rotational speed 0-8000 rpm and concluded that formability reaches a maximum of $8000 \mathrm{rpm}$ and remains the same for $10000 \mathrm{rpm}$. They also studied the temperature rise at the tool-sheet interface at different rotational speeds, using thermocouple. For AA6082-T6, a temperature value of about $160{ }^{\circ} \mathrm{C}$ is observed along the process, while for AA1050-H24, it was $130{ }^{\circ} \mathrm{C}[41,42]$. For magnesium alloys AZ31, the forming limit height only exceeds beyond tool rotational speed of $7000 \mathrm{rpm}$, and the formability improves at elevated temperature [37]. Buffa et al. studied the effect of tool rotation on grain size; no prominent change was noted up to $4000 \mathrm{rpm}$, but at 10,000 rpm, fine and equiaxed grains were observed near the bottom of the sheet [41].

The above description somehow discusses the repercussions of heat treatment and instant temperature rise in sheet forming during ISF. However, the relation between ISF process parameters and sheet performance is still vague during high-speed incremental sheet forming. In our study, the effects of preforming heat treatments, as well as sheet response during forming, were explored by varying tool rotational speed during incremental sheet metal forming while keeping the other process parameters fixed. Apart from other findings, the instant temperature changing trends at the tool-sheet interface and maximum temperature rise while increasing form tool speeds were majorly investigated. Moreover, the microstructural changes for pre- and post-process sheets are also reported.

\section{Materials and Methods}

Heat-treatment cycle, temperature variation measurements, sheet formability and microstructural study of pre- and post-process sheets are detailed in this section. 


\subsection{Heat-Treatment Cycle (AA2219-O to AA2219-T6)}

A sheet in annealed form of AA-2219-O was heat treated, as per the ASM handbook V.04 (Heat Treating) to AA-2219-T6 via the defined cycle shown in Figure 1, to increase its strength and to study its formability behavior at various tool rotational speeds during ISF.

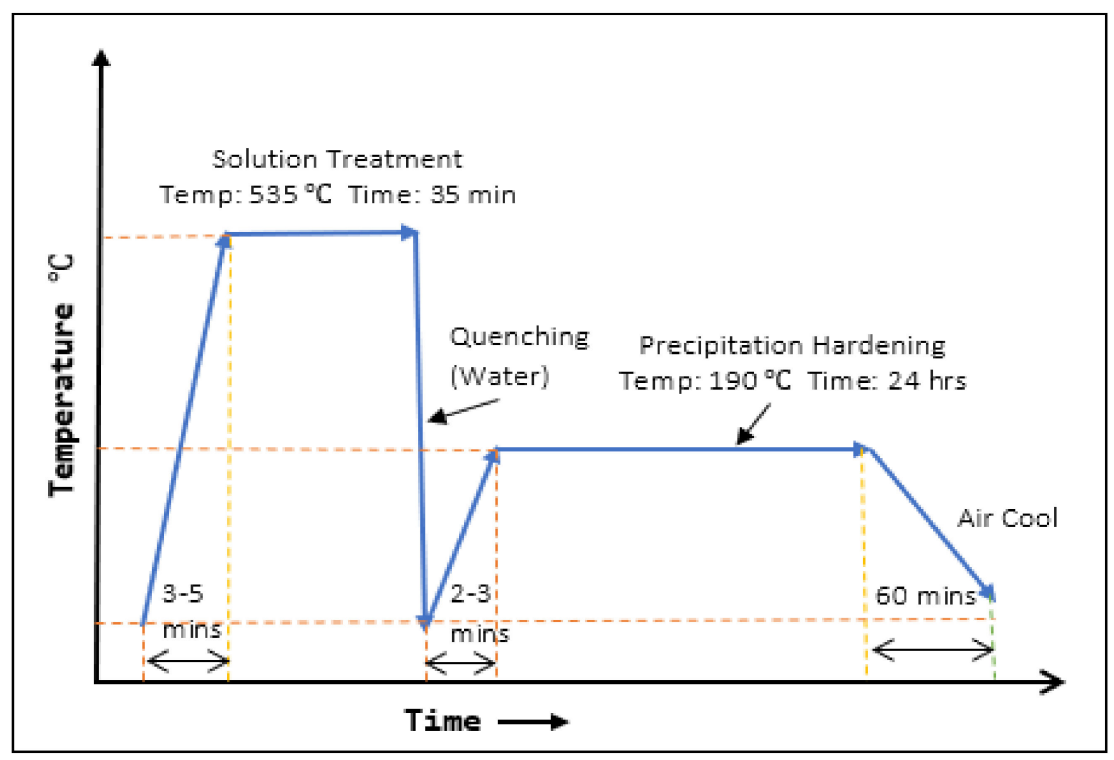

Figure 1. Heat-treatment cycle for T6 tempering.

Heat treatment to T6 changes the strength, ductility and hardness, which affect the performance measures during forming. Rectangular sheets of $110 \mathrm{~mm} \times 170 \mathrm{~mm}$ in annealed form were heat treated to solution treatment, followed by water quenching and then age hardening, as depicted in Figure 1. Sheets were properly placed in a furnace and heated at a constant temperature of $535^{\circ} \mathrm{C}$ for $35 \mathrm{~min}$, and all the precipitates dissolved in the aluminum matrix, which was then quickly immersed in water, resulting in the freezing of the microstructure in super-saturated solid solution, in very soft form. Then it was age/precipitation hardened in a furnace, at a constant temperature of $190{ }^{\circ} \mathrm{C}$, for $24 \mathrm{~h}$. In age-hardening, the second-phase particles precipitated out, resulting in the improvement of strength due to lattice strain. Likewise, the effect of the integrated solution-quenching-aging heat treatment on sheet forming was investigated and compared with annealed formed sheets. In addition, microstructural changes and temperature variations at the tool-sheet contact during incremental sheet forming were also analyzed.

\subsection{Material and Process Parameters}

AA-2219 is the aluminum alloy that was used in this experimental study; it is widely used in the aerospace industry. The elemental composition of AA-2219, as per supplier, is shown in Table 1, and composition was confirmed with EDS results. The major alloying element is copper with weight percent $(5.8 \%-6.8 \%)$. The sheets in annealed condition with $1.8 \mathrm{~mm}$ thickness and $170 \mathrm{~mm} \times 110 \mathrm{~mm}$ dimensions were used. Some of the sheets were heat treated to T6 condition for results comparison. The hemispherical forming tool of $12 \mathrm{~mm}$ diameter was used during incremental sheet forming where a tool feed rate of $3000 \mathrm{~mm} / \mathrm{min}$ and spiral tool path during forming and step size of $0.3 \mathrm{~mm}$ were selected, as per the literature study [24]. The draw angle of $45^{\circ}$ was kept constant during ISF for each sheet for better comparison. Experiments were conducted at variable tool rotational speeds of 50, 500, 1000, 1500, 2000, 2500 and $3000 \mathrm{rpm}$. Mineral oil was used during forming, in very small quantity, just to avoid damage of tool tip and sheet blank. The process setup is shown in Figure 2. 
Table 1. Chemical composition in weight percentage (aluminum alloy AA-2219).

\begin{tabular}{cccccccccccc}
\hline Components & Al & $\mathbf{C u}$ & Fe & Si & Mn & Mg & Zn & Ti & Others & V & Zr \\
\hline Weight \% & Bal & $5.80-6.80$ & $\begin{array}{l}0.30 \\
\max \end{array}$ & $\begin{array}{l}0.20 \\
\max \end{array}$ & $0.20-0.40$ & $\begin{array}{l}0.02 \\
\max \end{array}$ & $\begin{array}{l}0.10 \\
\max \end{array}$ & $0.02-0.10$ & $\begin{array}{l}0.05 \text { each } \\
0.15\end{array}$ & $0.05-0.15$ & $0.10-0.25$ \\
\hline
\end{tabular}
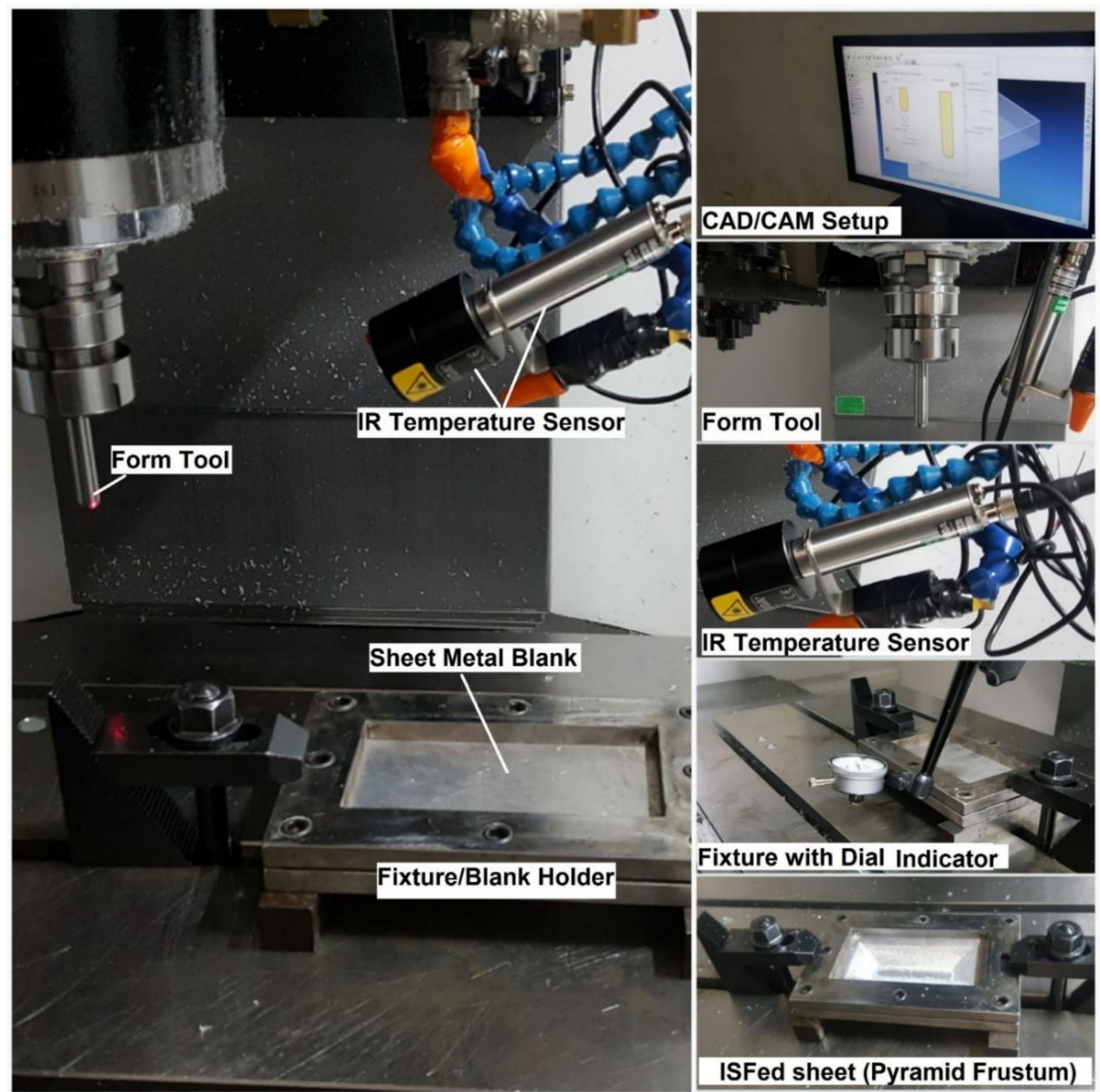

Figure 2. ISF process setup.

\subsection{Microstructure Study}

In order to investigate the effect of variation in the tool rotational speed on the sheet microstructure, a square sample of $10 \mathrm{~mm} \times 10 \mathrm{~mm}$ was extracted, using an EDM wire-cut machine (Model: FR-500, manufacture by Ruijun, China), from the lateral surfaces of each formed sheet, at a depth of $10 \mathrm{~mm}$, as depicted in Figure 3a. We studied the micro-detail images for size and density variation of second-phase particles during ISF, and then the image results were concluded by comparing with the microstructure of unformed sheet blanks. The extracted samples from formed sheets were mounted in opaque Bakelite powder through a sintering process $\left(158^{\circ} \mathrm{C}, 145 \mathrm{~kg} / \mathrm{cm}^{2}, 4-5 \mathrm{~min}\right)$, using a mounting press machine for easily gripping during grinding and polishing, as shown in Figure $3 \mathrm{~b}$. The samples were then subsequently ground up to P3000 with SiC paper and then polished with velvet cloth and diamond paste. To get a fine-polished surface, Kemet oil was used on the polishing wheel. After polishing and washing the samples with water, we etched them according to the ASM 
Handbook V.09 (metallography and microstructures), using Keller's reagent (RICCA chemical company, Arlington, Texas), with an etching time of 8-15 s. The etched samples were then studied for microscopic analysis with a scanning electron microscope (Model: IT100LA, JEOL Ltd. Tokyo, Japan), as shown in Figure 3c.
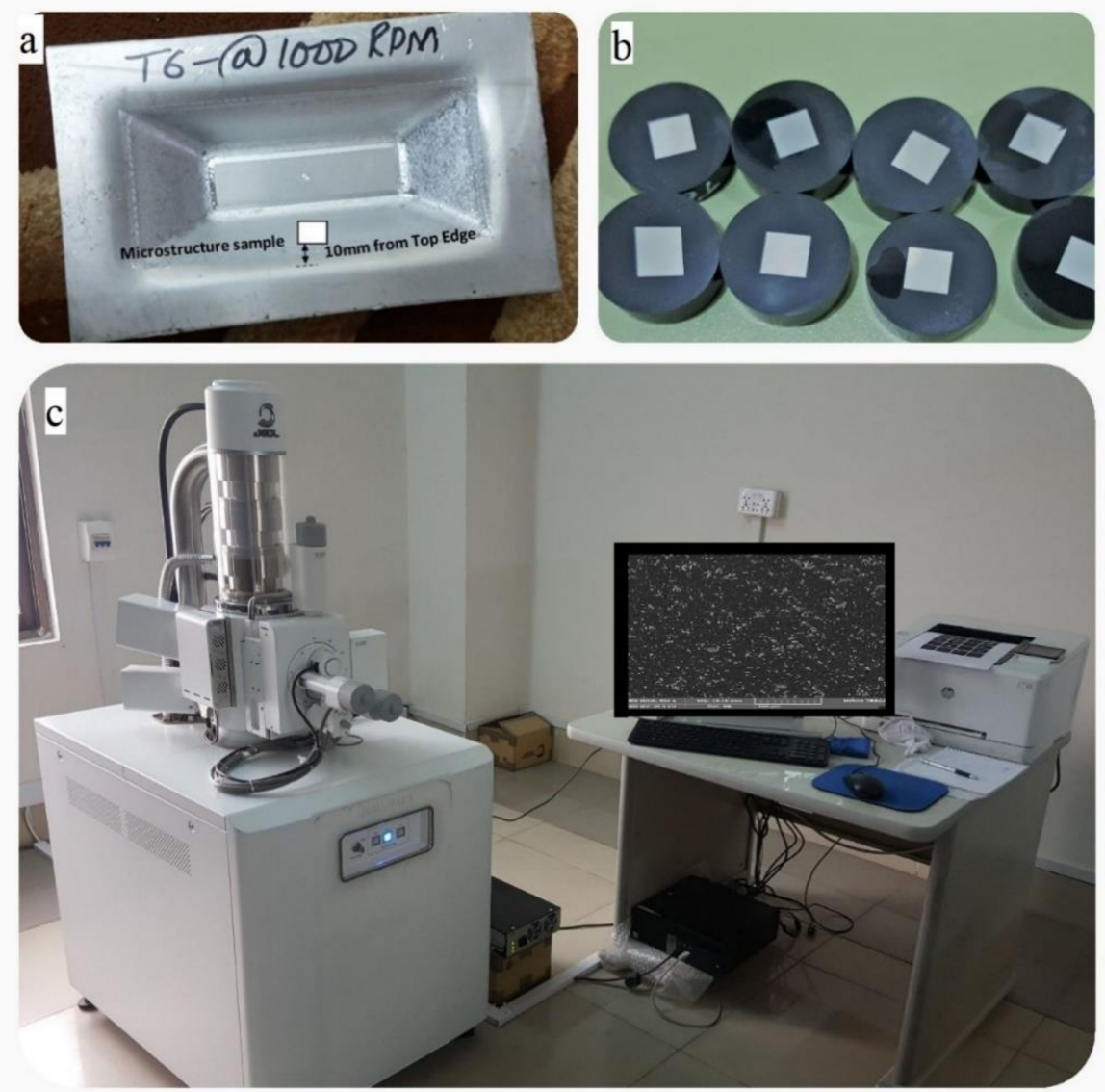

Figure 3. Metallography details: (a) sample extraction, (b) molded metallography samples and (c) scanning electron microscope (Model: IT100LA, JEOL Ltd. Tokyo, Japan).

\subsection{Temperature Measurement and Emissivity Calculation}

Sheet forming was performed on a CNC machine tool (Hartford LG-800, She Hong Industrial Co. Ltd, Taichung, Taiwan), and parts models were made in Creo software 4.0 (Parametric Technology Corporation PTC, Boston, MA, USA), as shown in Figure 4, and then imported to PowerMill Pro 8.0 software (developed by Autodesk Inc., San Rafael, CA USA) for codes generation and navigating forming tool parameters, as per requirements. A fixture having two rectangular halves was used for sheet clamping during ISF, as shown in Figure 2.

In most of the research studies, the local temperature rise was measured by placing the thermocouple on the reverse side of the sheet-blank instead of the surface formed by the form tool [37]. In our study, the temperature rise was measured directly at the tool-sheet contact point, using a non-contact temperature sensor. To eliminate issues and errors in measurement, a non-contact infrared temperature sensor was used to record the temperature. It was very difficult to accurately measure the instant temperature rise; therefore, variation profile and maximum temperature rise at the tool/sheet contact zone were recorded with the IR temperature sensor. Before the forming of the sheet blank, emissivity was calculated at different temperatures, and then an average value was selected. A series of experiments were performed to record the proper value for emissivity of 0.72 for an annealed sheet and 0.69 for a T6 sheet. The emissivity value is dependent on the sheet surface and varies with 
temperature and can introduce error in recorded data. An infrared temperature sensor (OS150-2USB, Omega Engineering, Inc. Norwalk, CT, USA), as depicted in Figure 2, was used to record the instant temperature rise and maximum temperature during the ISF process. The sensor was mounted by using a magnetic stand near the tool spindle, while maintaining the manufacturer-recommended distance between the tool and blank. The laser beam trajectory was targeted at the tool tip. The clamping or mounting was made in such a way that the sensor moved in coherency with the tool movement, to record the temperature accurately. The tabulated values were noted in dedicated software of temperature sensor, i.e., OmegaSoft V.1.27. The tabulated data were then transformed into a graph, through the use of Microsoft Excel, as shown in Figure 6 and Figure 8. A series of experiments were conducted to record the temperature profile at varying tool speeds, ranging from 50 to $3000 \mathrm{rpm}$. The results obtained for both sheets (annealed and T6) were then compared. The pyramid frustums at a fixed draw angle of $45^{\circ}$ were produced through CNC Mill (Hartford LG-800, She Hong Industrial Co. Ltd, Taichung, Taiwan), in order to investigate the formability of sheet to forming depth up to $25 \mathrm{~mm}$.
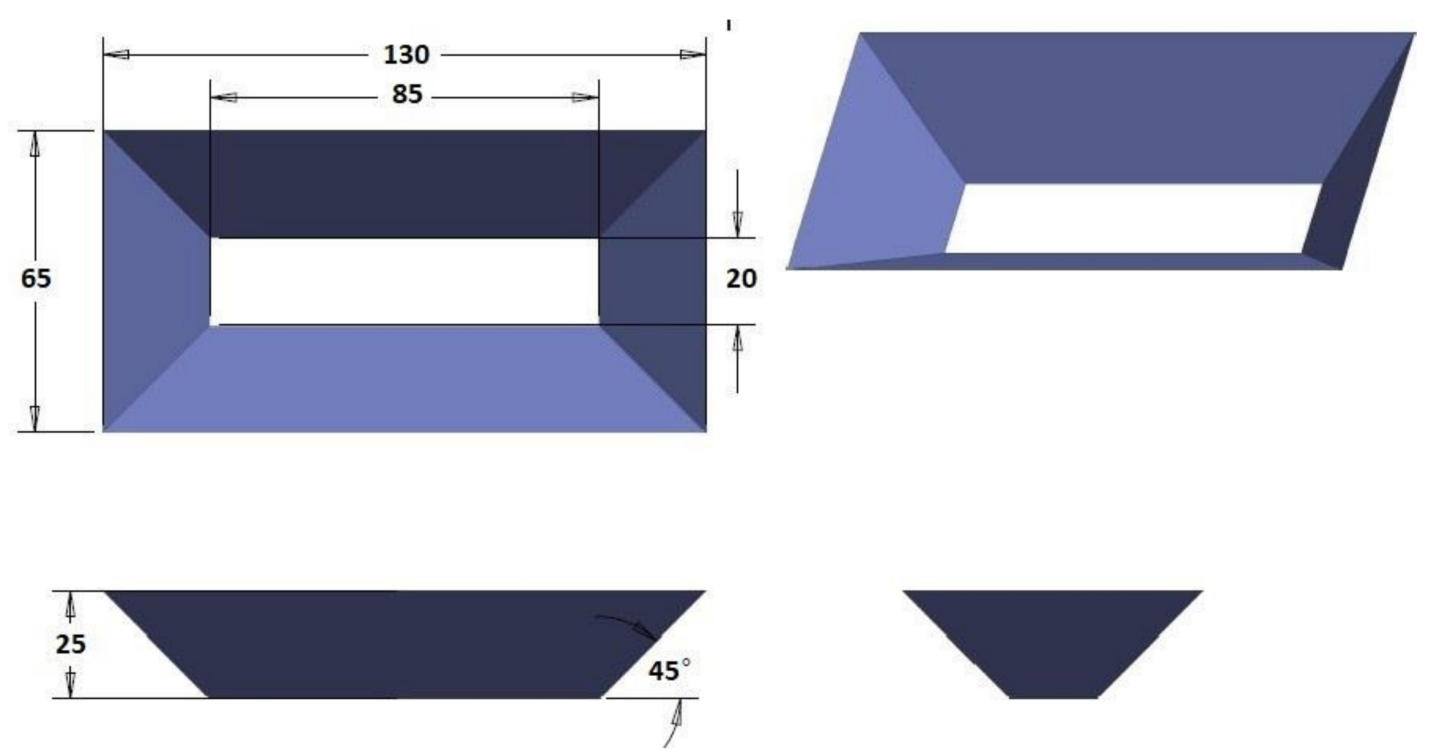

Figure 4. Creo model of fixed wall angle pyramidal frustum: dimensions are given in $\mathrm{mm}$.

To summarize the methodology in the current study, an experimental setup was made to form the blank sheets of Al-2219 aluminum alloy to pyramid frustum of fixed wall angle. The annealed sheets AA-2219-0 were heat treated to T6 condition, i.e., AA-2219-T6. The tool rotational speed was the only variable parameter, while fixed incremental pitch and feed rate were selected. The temperature profile and maximum temperature rise were measured during incremental sheet forming, using a non-contact IR temperature sensor, by directing the laser beam at the point of contact between the forming tool and sheet blank. A micro-examination was performed to explain the microstructure variation for the defined series of variable tool speeds. For statistics and results confirmation, each set of process parameters was checked for two sheets, for the best conclusions, and almost the same response was obtained in terms of fracture and formed parts.

\section{Results and Discussion}

In the current work, the heat-treatment effects, sheet formability, temperature variation trends and microstructure changes are experimentally investigated by varying tool speeds, ranging from 50 to $3000 \mathrm{rpm}$ for annealed and T6 sheets of AA-2219 aerospace alloy. High tool speed affects the strain rates and formability, and the temperature varies due to tool-blank friction during forming. 


\subsection{Success Status of Parts and Temperature Profiles}

The success status of annealed and T6 parts is shown in Table 2. In the range of 50-3000 rpm of tool, all the sheets in annealed condition were successfully formed to a forming depth of $25 \mathrm{~mm}$, with a forming wall angle of $45^{\circ}$. On the other hand, the in case of T6 sheets of the same alloy, the sheet successfully formed only in the range of 50-2000 rpm, under the same forming conditions. Upon exceeding speed beyond $2000 \mathrm{rpm}$, the T6 sheet fractured before reaching a forming depth of $25 \mathrm{~mm}$. Forming depth measuring setup and representatives of successful and unsuccessful samples are shown in Figure 5.

During forming at various tool rotational speed, the temperature rises at the sheet tool interface due to relative motion between the tool and sheet. The temperature rise during forming affects the mechanical properties of the material, producing a softening effect, thereby resulting in enhanced sheet formability [41]. This can be easily observed in the annealed sheet, as the parts over the entire range of rotation could be successfully formed to a forming depth of $25 \mathrm{~mm}$. Interestingly, it does not apply to T6 sheets, specifically once exceeding the rotational speed of $2000 \mathrm{rpm}$, wherein part failure was observed before reaching the defined forming depth of $25 \mathrm{~mm}$. In fact, though temperature rise softens the material, this also reduces the viscosity of the liquid lubricant, thereby adversely affecting its lubrication performance. Such a condition, if it develops, can increase the friction stress than the shear yield strength of the material, thereby leading to sheet fracturing. As comparable from the temperature profiles presented in Figure 6 and Figure 8, the temperature rising rate in the T6 sheet is greater than that in the annealed sheet. This suggests that the friction at the tool/sheet interface was higher while forming the T6 sheet than forming the annealed sheet. Furthermore, the lubricant could not overcome the friction effects due to elevated temperature, consequently causing sheet failure before reaching the defined depth of $25 \mathrm{~mm}$. Another possible reason could be the accumulation of particles, whose density is greater in T6 sheet than in the annealed sheet, at the tool/sheet interface. However, this point requires further investigation in the future, when taking combined effect of temperature and friction into account. These results suggest to use high-performance lubricants to overcome frictional effects, to ensure the successful forming of parts, especially those of the T6 sheet.

Table 2. Success status of T6 and annealed parts: height $=25 \mathrm{~mm}$, forming angle $=45^{\circ}$ and tool diameter $=12 \mathrm{~mm}$.

\begin{tabular}{|c|c|c|c|c|}
\hline SHEET-RPM & $\operatorname{TMAX}\left({ }^{\circ} \mathrm{C}\right)$ & \multicolumn{2}{|c|}{$\begin{array}{l}\text { Forming Depth } \\
\text { Achieved (MM) }\end{array}$} & Status \\
\hline A-50 & 36.2 & \multicolumn{2}{|c|}{25} & Successful \\
\hline A-500 & 44.4 & \multicolumn{2}{|c|}{25} & Successful \\
\hline A-1000 & 88.4 & 25 & 25 & Successful \\
\hline A-2000 & 164.9 & 25 & 25 & Successful \\
\hline A-3000 & 254 & \multicolumn{2}{|c|}{25} & Successful \\
\hline T6-50 & 40 & 25 & 25 & Successful \\
\hline T6-500 & 52.5 & 25 & 25 & Successful \\
\hline T6-1000 & 84.4 & \multicolumn{2}{|c|}{25} & Successful \\
\hline T6-2000 & 118.1 & 25 & 25 & Successful \\
\hline T6-2500 & 230.1 & 17.8 & 16.9 & Fracture \\
\hline T6-3000 & 163.3 & 13.3 & 12.9 & Fracture \\
\hline
\end{tabular}




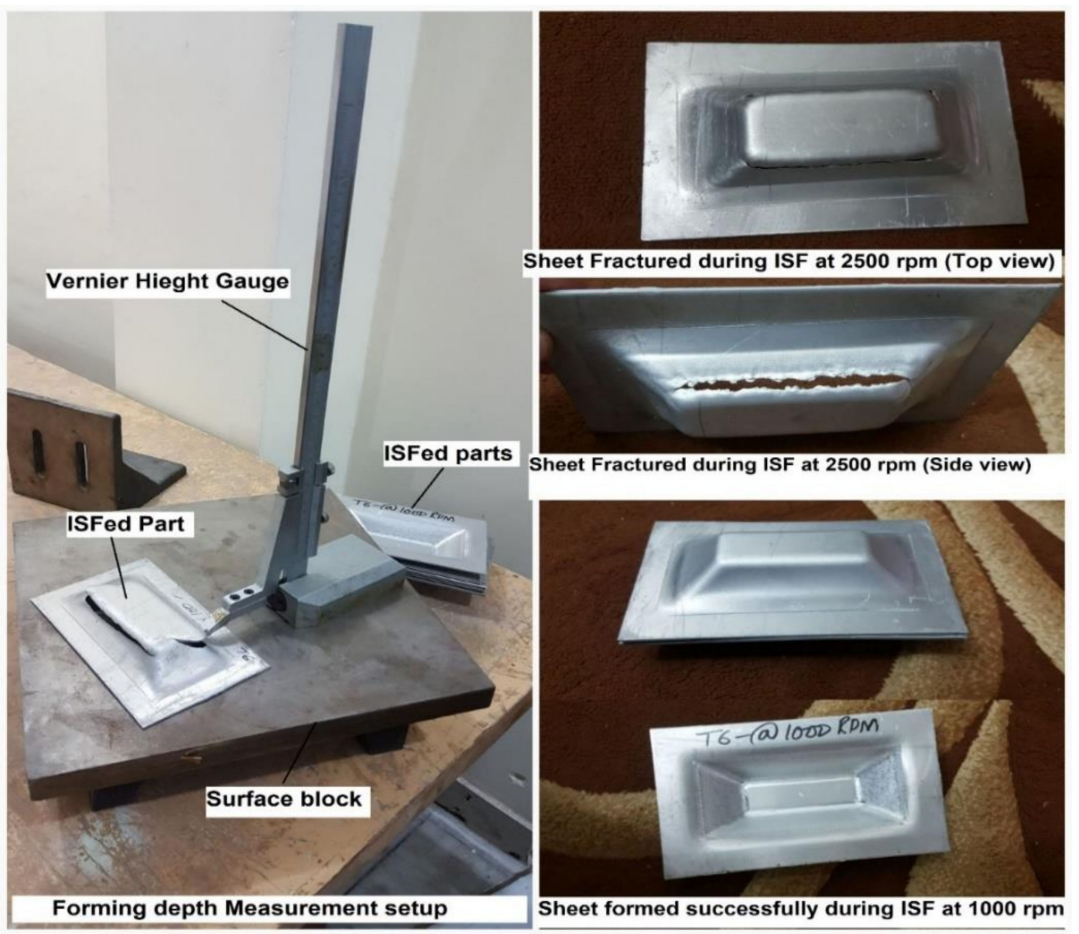

Figure 5. Setup showing measurement of forming depth and representatives of successful and unsuccessful samples.

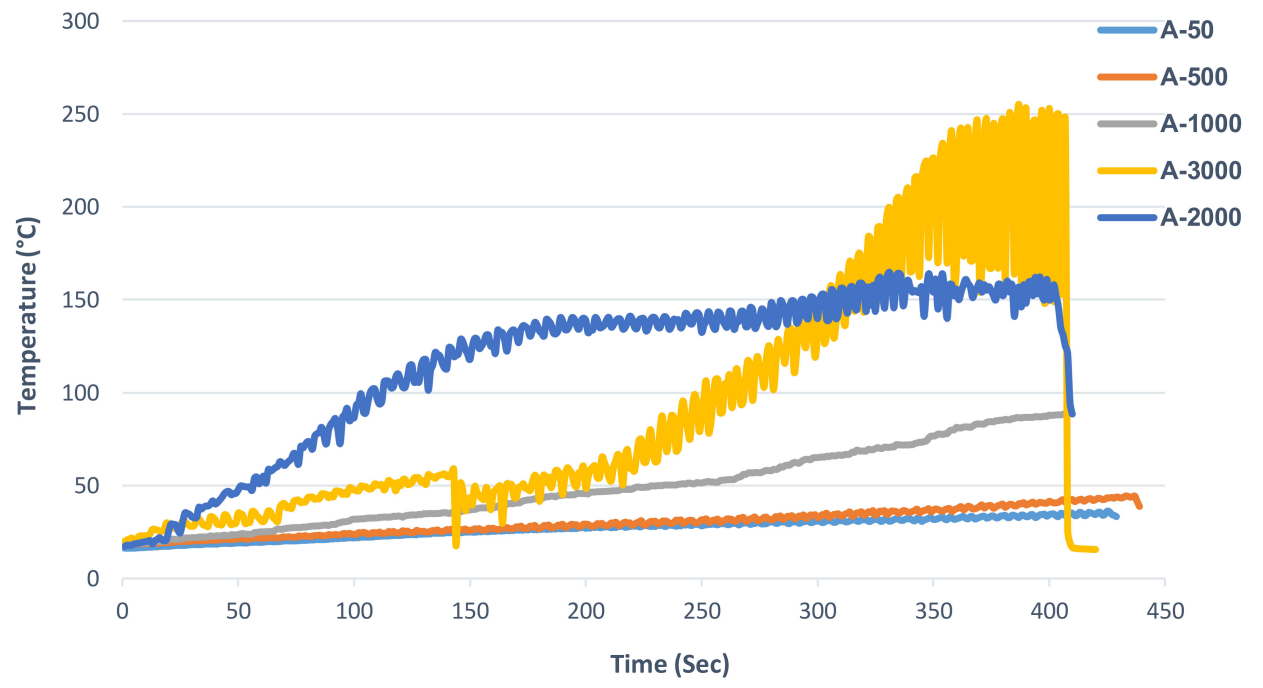

Figure 6. Temperature profiles at varying rotational speed, as observed during ISF of annealed AA-2219 sheet.

The temperature variation trends and maximum temperature recorded for annealed sheets at various tool rotational speed are shown in Figures 6 and 7, respectively. It is noted that all temperature profiles during forming follow the same variation trend almost for all ISF sheets. In the case of annealed sheets, forming up to $25 \mathrm{~mm}$ is successfully achieved without rupture for all the experimental tool speeds from 50 to $3000 \mathrm{rpm}$. Similarly, temperature profiles and maximum temperature recorded for T6 sheets at various tool rotational speeds are shown in Figures 8 and 9, respectively. The temperature variation trend shows that the temperature rising slope increases with the increase in tool speed. Exceeding a tool speed beyond $2000 \mathrm{rpm}$ leads to sheet fracture, and significant variation of thermal 
rise is noticed, as depicted in Figure 9, with red vertical bars. The temperature shoots to higher values beyond $2000 \mathrm{rpm}$, because high tool rotation and incremental tool forces are subsequently trying to form the sheet to the defined depth. However, high strength and lack of elongation is continuously resisting the tool force, which results in continuous temperature rise due to sheet-tool interaction and causes sheet rupture. The noisy bumps in each temperature variation graph in Figures 6 and 8 can be seen because, in each spiral path cycle followed by the tool during incremental depth or pitch depth, the tool tip faces the fixture wall side and becomes off seen from the sensor, resulting in a sudden drop in temperature, as shown in the trend. If we compare maximum temperature rise during forming for both sheets, under the same tool speed, as shown in Figure 10, it is observed that the temperature rise almost resembles up to $1000 \mathrm{rpm}$, but then maximum temperature rise decreases for T6 comparatively and then shoots to higher values beyond $2000 \mathrm{rpm}$. Consequently, it is observed that, in order to have successful part with draw angle of $45^{\circ}$, the tool rotational speed for AA2219-T6 should be up to $2000 \mathrm{rpm}$, as a tool speed beyond $2000 \mathrm{rpm}$ results in fractured geometries. Meanwhile, in case of AA2219-O, any tool rotational speed can be selected in the defined range.

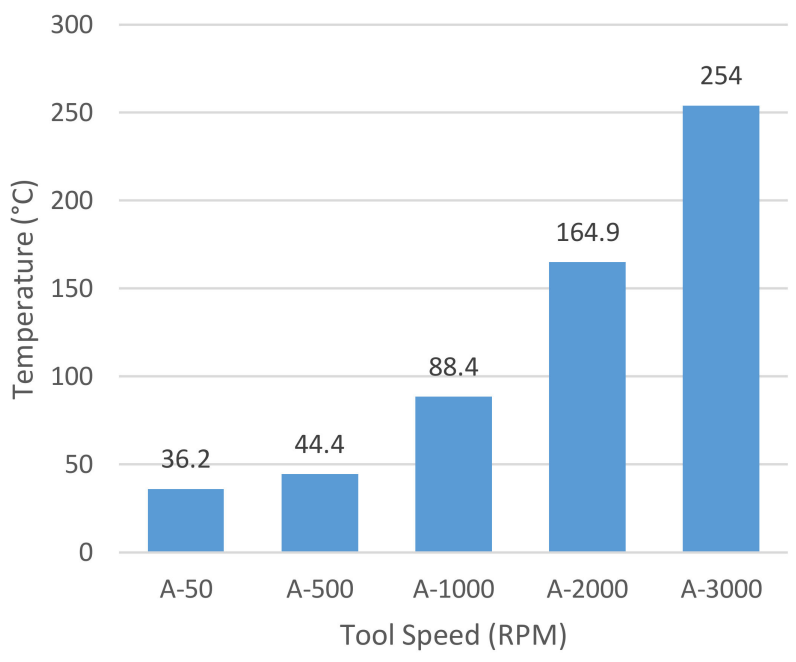

Figure 7. Maximum temperature rises at varying rotational speed, as observed during ISF of annealed AA-2219 sheet.

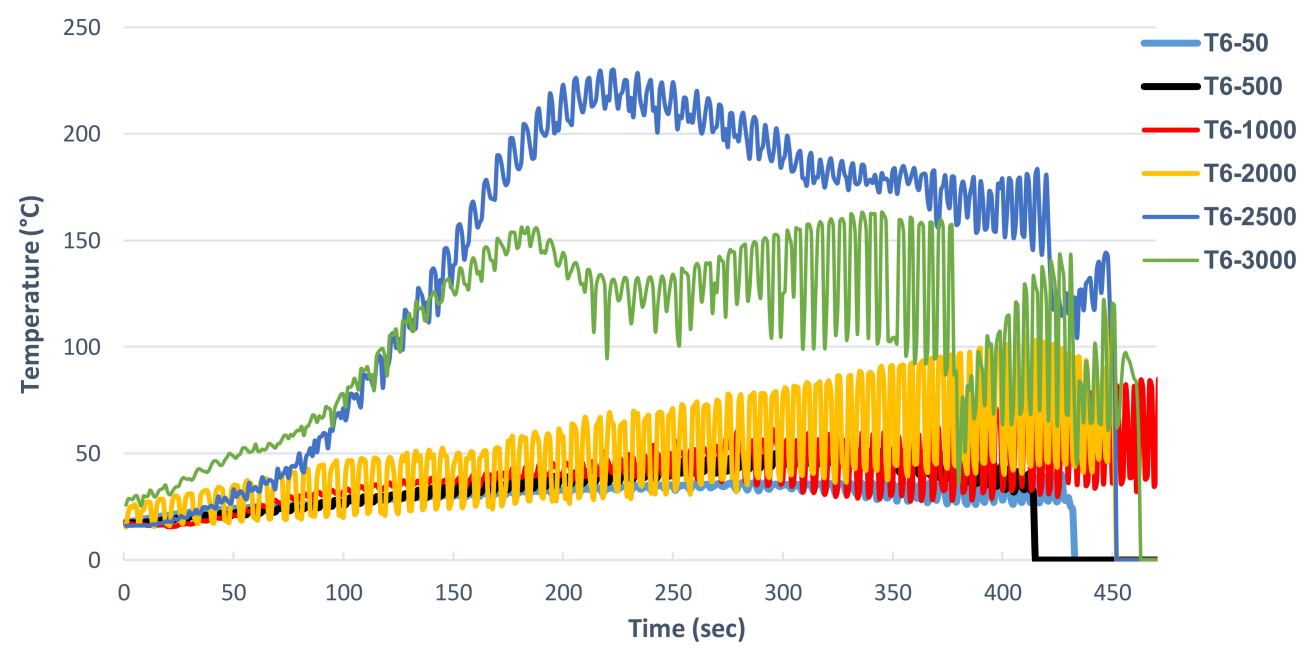

Figure 8. Temperature profiles at varying rotational speed, as observed during ISF of T6 AA-2219 sheet. 


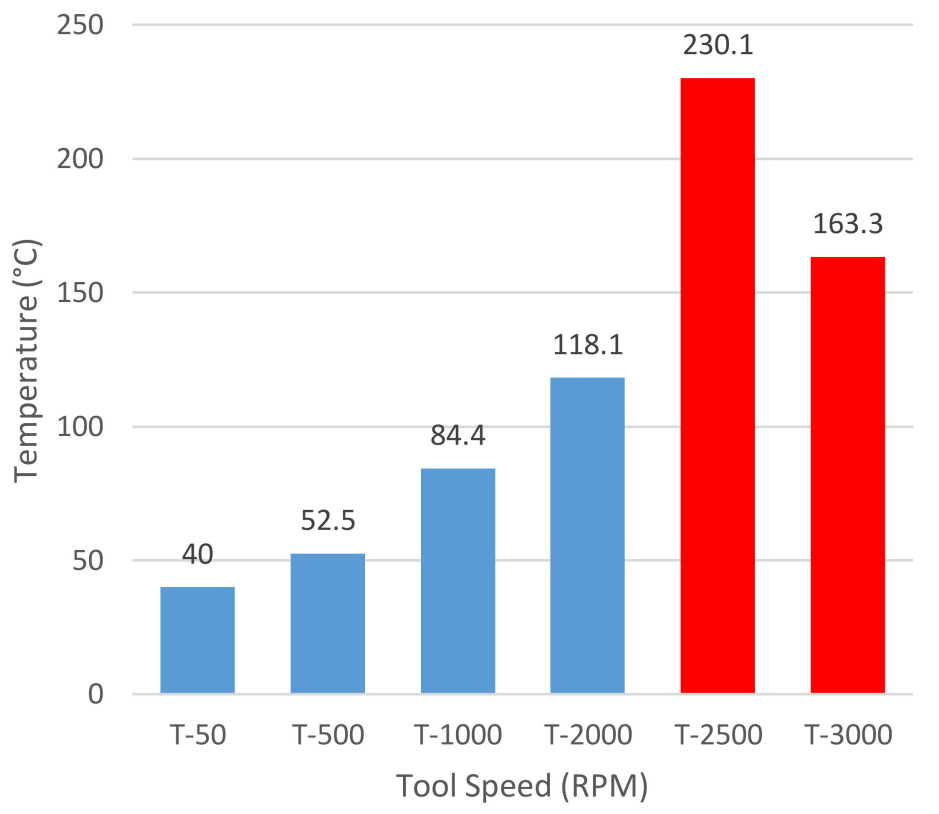

Figure 9. Maximum temperature rises as a function of rotational speed during ISF of T6- AA-2219 sheet: red bars represent fractured T6 parts.

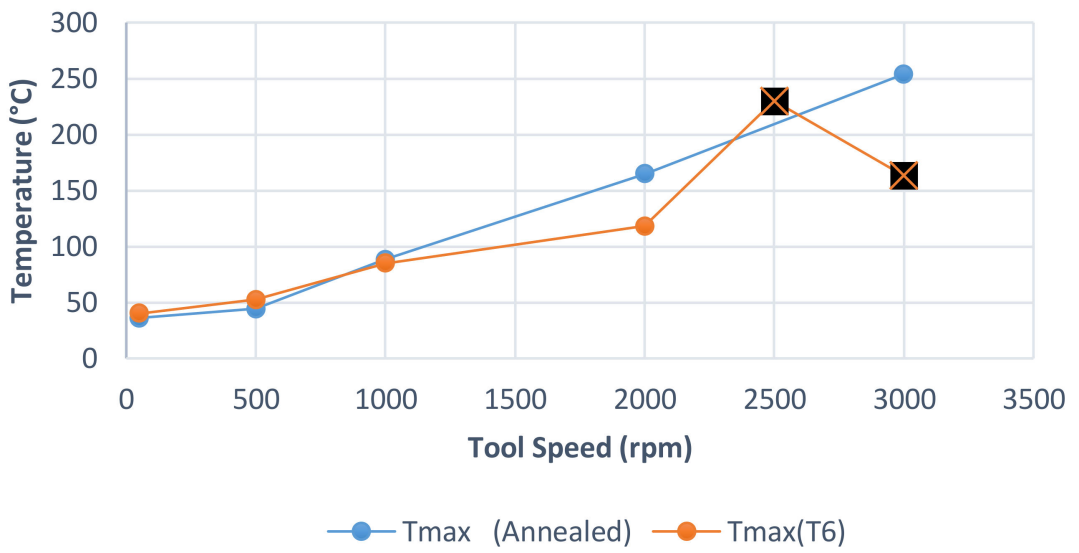

Figure 10. Comparison for maximum temperature rises at different tool speed for annealed and T6 sheets (black $x$ dots show failure of sheet before $25 \mathrm{~mm}$ at the respective $\mathrm{rpm}$ ).

Tables 3 and 4 shows maximum temperature noticed, percent temperature changes with respect to consecutive tool speed and temperature increase for each tool speed with respect to $50 \mathrm{rpm}$ for both tempers. For annealed and T6 samples, rising trend in temperature variation is noticed with increasing tool speed. The red values in Table 4 shows fractured samples while forming T6 blank beyond $2000 \mathrm{rpm}$.

\subsection{Heat Treatment and ISF Effects on Microstructure of Aluminum Alloy Sheets AA-2219}

The effects of heat treatment and ISF at variable tool speeds on the density and size of second-phase particles for annealed and T6 sheets were studied. The quantity and average size of second-phase particles were estimated by using 'ImageJ' software (V.1.49. developed by NIH) and are listed in Table 5 . The particles densities were investigated quantitatively for preformed and post-ISF annealed and T6 sheets, respectively, and summarized in Table 5 and shown in Figure 11. If annealed blank is compared with T6 blank, it can be seen that, after heat treatment of annealed blank to T6 blank, the density of particles become doubled. It is also noticed that, for annealed sheets, the density of particles decreases 
continuously as the tool speed increases during ISF, and at a speed of 2000, the density of particles decreased by $81 \%$. Moreover, in the case of T6 sheets, the density of particles also decreased by $93 \%$ as tool rpm was increased, like in case of annealed formed sheets. It is concluded that particles' density decreases as tool speed increases for both sheets, and particle density in T6 sheets is almost double as compared to annealed sheets. In addition, if we compare average particle size, the particle size in annealed blank is almost double the size of T6 blank, and the trend remains the same during forming at increasing tool speed. It can be seen that particle size slightly decreases among annealed sheets and shows a trivial increase in T6 sheets with increase in tool speed during ISF. It means that heat treatment of an annealed to a T6 sheet results in the reduction in particle size and increases in particles density, as depicted in Table 5. The ISF of annealed sheets results in the slight reduction of particle size as the tool speed increases from 50 to $2000 \mathrm{rpm}$, unlike T6 sheets, where particle size increases. The particle densities for both sheets decreased with the increase in tool speed during ISF.

Table 3. Maximum temperature rises during ISF of annealed samples and percent increase in maximum temperature at varying tool rotation.

\begin{tabular}{lccc}
\hline Sheet-RPM & $\mathbf{T}_{\text {MAX }}\left({ }^{\circ} \mathbf{C}\right)$ & Temp. change $\%$ & Temp. Increase \% with respect to A-50 \\
\cline { 1 - 3 } A-50 & 36.2 & & \\
\hline A-500 & 44.4 & 18.5 & 18.5 \\
\hline A-1000 & 88.4 & 49.8 & 59.0 \\
\hline A-2000 & 164.9 & 46.4 & 78.0 \\
\hline A-3000 & 254 & 35.1 & 85.7 \\
\hline
\end{tabular}

Table 4. Maximum temperature rises during ISF of T6 samples and percent increase in maximum temperature at varying tool rotation.

\begin{tabular}{lccc}
\hline Sheet-RPM & $\mathrm{T}_{\text {MAX }}\left({ }^{\circ} \mathrm{C}\right)$ & Temp. change $\%$ & Temp. Increase \% with respect to T-50 \\
\cline { 1 - 3 } T6-50 & 40 & \multicolumn{2}{c}{} \\
\hline T6-500 & 52.5 & 23.81 & 23.81 \\
\hline T6-1000 & 84.4 & 37.80 & 52.61 \\
\hline T6-2000 & 118.1 & 28.54 & 66.13 \\
\hline T6-2500 & 230.1 & 48.67 & 82.62 \\
\hline T6-3000 & 163.3 & -40.99 & 75.49 \\
\hline
\end{tabular}

Table 5. Summary of SEM analysis for second-phase particles in successfully formed sheets.

\begin{tabular}{lccc}
\hline \multicolumn{1}{c}{ Samples } & Surface particles $/ \mathbf{m m}^{\mathbf{2}}$ & Average area of particle $\left(\boldsymbol{\mu m}^{\mathbf{2}}\right)$ & Average Diameter $(\boldsymbol{\mu m})$ \\
\hline Annealed blank & $229,404.00 \pm 3200$ & $8.33 \pm 2.7 \%$ & $3.26 \pm 1.5 \%$ \\
\hline A-50 & $201,461.00 \pm 4300$ & $8.19 \pm 1.8 \%$ & $3.23 \pm 1.5 \%$ \\
\hline A-1000 & $132,041.00 \pm 3400$ & $7.72 \pm 2.2 \%$ & $3.14 \pm 1.2 \%$ \\
\hline A-2000 & $28,138.00 \pm 5600$ & $7.11 \pm 2.1 \%$ & $3.01 \pm 1.3 \%$ \\
\hline T6 Blank & $500,060.00 \pm 8700$ & $1.93 \pm 1.6 \%$ & $1.58 \pm 0.9 \%$ \\
\hline T6-50 & $463,809.00 \pm 7300$ & $2.25 \pm 3.5 \%$ & $1.69 \pm 1.4 \%$ \\
\hline T6-1000 & $286,020.00 \pm 4300$ & $2.44 \pm 2.0 \%$ & $1.77 \pm 1.4 \%$ \\
\hline T6-2000 & $42,955.00 \pm 5100$ & $2.74 \pm 3.5 \%$ & $1.87 \pm 1.1 \%$ \\
\hline
\end{tabular}



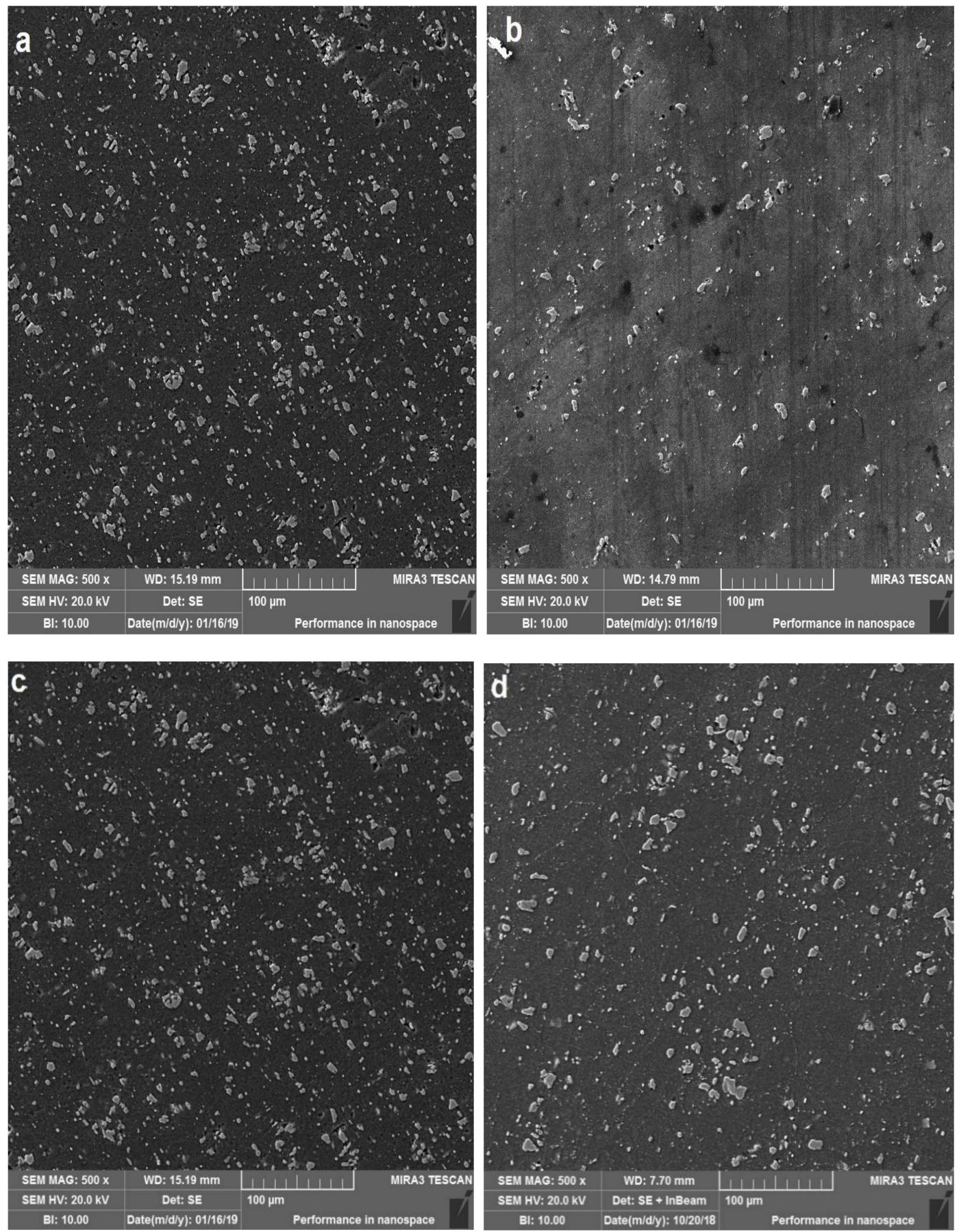

Figure 11. Cont. 

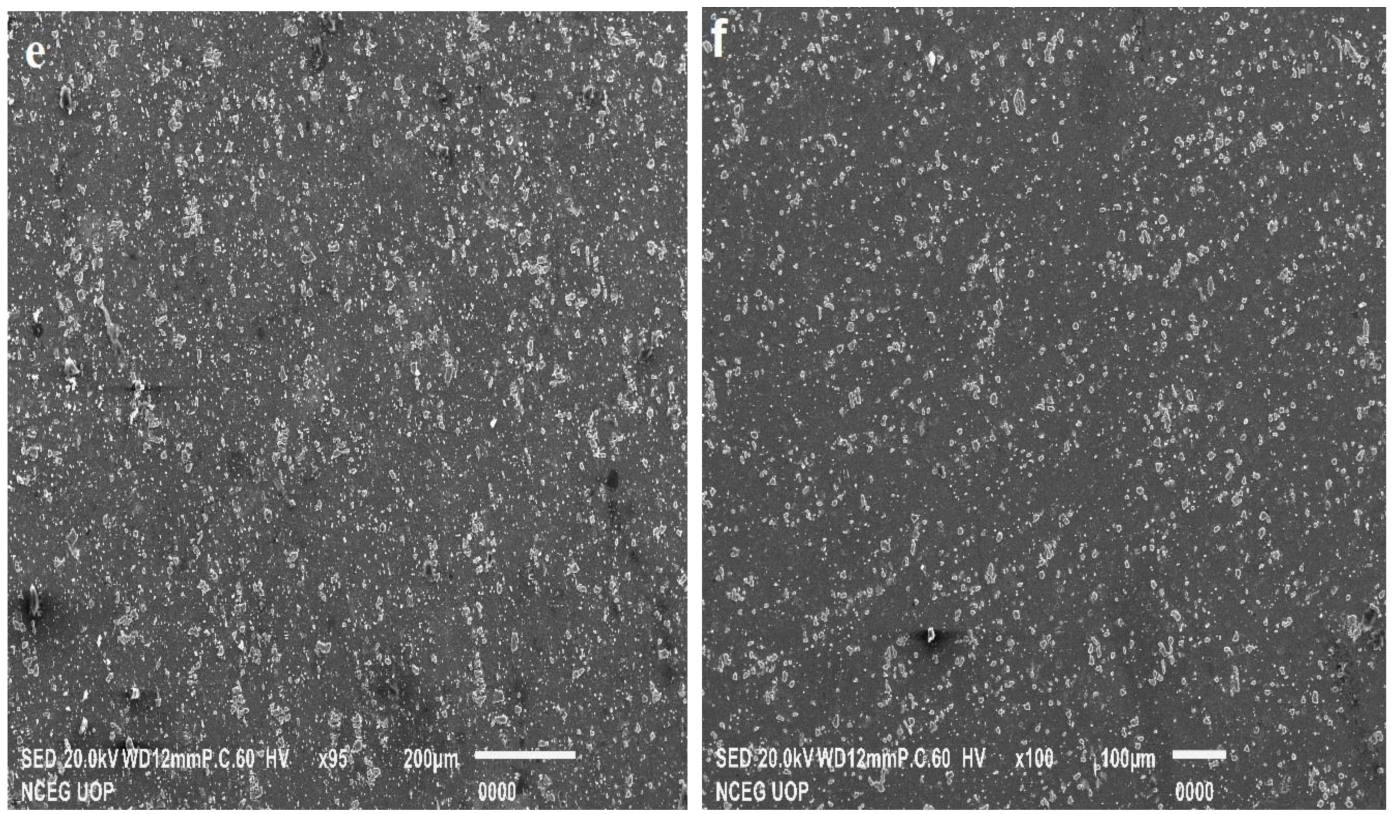

Figure 11. SEM image of (a) T6-2000, (b) A-2000, (c) T6-50, (d) A-50, (e) T6 blank and (f) annealed blank.

Figures 12 and 13 show EDS report in elemental form in weight percent, as well as in atomic percent, for the preformed blank and successfully formed sheets. The result shows that weight $\%$ of copper varies in the range of 6.38-7.48 in aluminum. The oxygen element is reported only in annealed sheet at $2000 \mathrm{rpm}$, but in negligible quantity while in T6 sheet, the oxygen element is zero for the same tool speed.

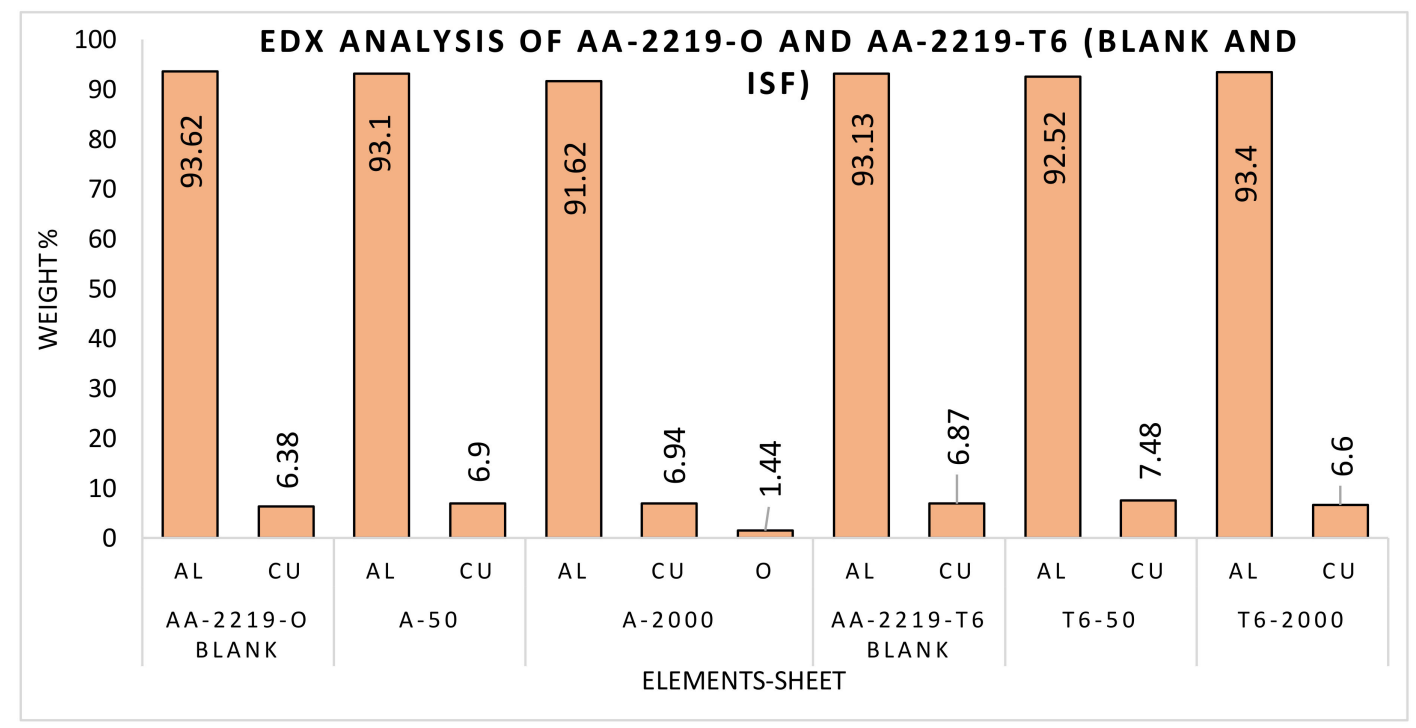

Figure 12. EDX analysis of parent sheets and formed parts (elemental composition in weight percentage). 


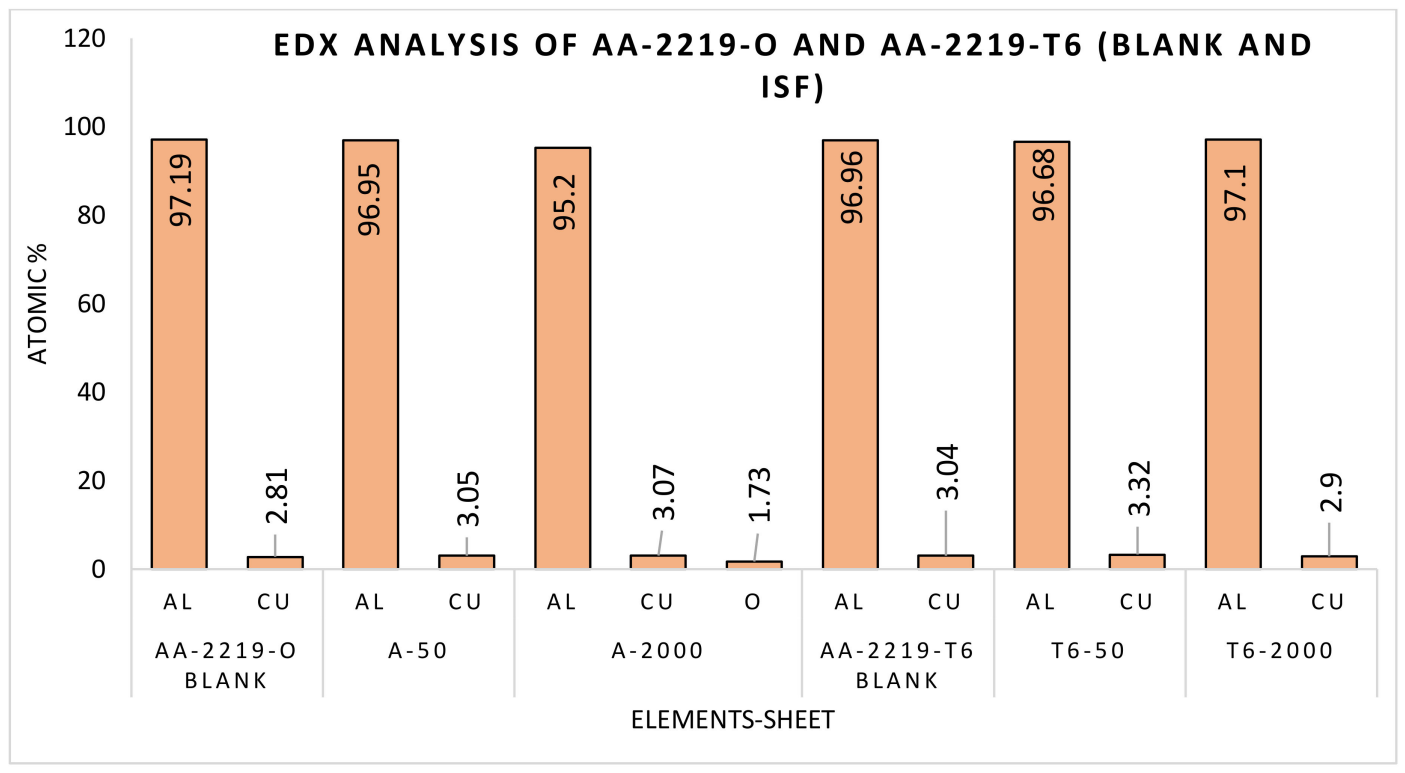

Figure 13. EDX analysis of parent sheets and formed parts (elemental composition in atomic percentage).

\section{Conclusions}

The present study was performed with an aim to investigate the influence of rotational speeds on temperature variation and microstructures of AA2219 aerospace alloy in two temper conditions. The results showed that the tool rotational substantially affects the temperature and thus the microstructure of the alloy in both tempers. These variations, in turn, affect the forming success of the parts in ISF. The following important conclusions can be drawn from the study:

1. The forming temperature of both the annealed and tempered alloys increases with the increase of the rotational speed of the tool. However, in general, the peak temperature noted and rising rate in the T6 alloy were higher than that in the annealed alloy. Specifically, the peak temperature in the annealed alloy ranged from 36 to $165^{\circ} \mathrm{C}$, and that in the annealed alloy ranged from 40 to $118^{\circ} \mathrm{C}$ in the investigated range of speed.

2. Both the annealed and T6 tempered alloys contained second-phase particles. The density of these particles upon forming was reduced with increasing intensity with the rotational speed, thereby showing the influence of forming-induced temperature rise on the particle's density. This particularly ranged from $229,404 \pm 3200$ to $28,138 \pm 5600$ in the annealed alloy and 500,060 \pm 8700 to $42,955 \pm 5100$ in the T6 alloy. The two tempers of AA2219 alloy, however, showed a trivial response to speed variation. When we increased the rotational speed, the particle size received a slight change in the two types of tempers.

3. As a result of temperature variation due to changing rotational speed, the forming success of material was affected, specifically that of T6 alloy. Exceeding the speed beyond $2000 \mathrm{rpm}$ caused premature failure of T6 alloy before reaching the depth of $25 \mathrm{~mm}$, reasoning to intensive rate of temperature rise. This result dictates that an increased friction at the tool/interface could lead to premature failure and thus leads to the conclusion that high-performance lubricants should be used to curb the friction effects at elevated temperatures. In the case of the annealed alloy, no failure was observed in the entire range of rotational speed, because the temperature rising rate remained lower than that observed for T6 alloy under equivalent process conditions.

Author Contributions: Funding acquisition, M.A.; Investigation, A.A.R.; Project administration, M.N.K.; Resources, S.K.; Supervision, N.U. and G.H.; Writing-Original draft, A.A.R., G.H., M.A \& N.U.; Writing-review editing, A.A.R., G.H., M.A \& N.U. All authors have read and agreed to the published version of the manuscript.

Funding: The authors are grateful to the Raytheon Chair for Systems Engineering for funding. 
Acknowledgments: The authors are grateful to the Raytheon Chair for Systems Engineering for funding. The authors would also like to acknowledge the Peshawar Light Engineering Center (PLEC) and GIK Institute for technical support and for providing research facilities. We would like to thank Riaz Muhammad and Muftooh Ur Rehman Siddique for their support.

Conflicts of Interest: The authors declare that they have no conflict of interest.

\section{References}

1. Hagan, E.; Jeswiet, J. A review of conventional and modern single-point sheet metal forming methods. Proc. Inst. Mech. Eng. Part B J. Eng. Manuf. 2003, 217, 213-225. [CrossRef]

2. Lange, K. Handbook of Metal Forming; McGraw-Hill B.Company: New York, NY, USA, 1985; p. 1216.

3. Quigley, E.; Monaghan, J. Metal forming: An analysis of spinning processes. J. Mater. Process. Technol. 2000, 103, 114-119. [CrossRef]

4. Emmens, W.C.; Sebastiani, G.; van den Boogaard, A.H. The technology of incremental sheet forming-A brief review of the history. J. Mater. Process. Technol. 2000, 210, 981-997. [CrossRef]

5. Roy, M.J.; Klassen, R.J.; Wood, J.T. Evolution of plastic strain during a flow forming process. J. Mater. Process. Technol. 2009, 209, 1018-1025. [CrossRef]

6. Shim, M.-S.; Park, J.-J. The formability of aluminum sheet in incremental forming. J. Mater. Process. Technol. 2002, 113, 654-658. [CrossRef]

7. Amino, H.; Lu, Y.; Ozawa, S.; Fukuda, K.; Maki, T. Dieless NC forming of automotive service panels. Advd Technol. Plast. 2002, 2, 1015-1020.

8. Jeswiet, J.; Hagan, E. Rapid prototyping of a headlight with sheet metal. Can. Inst. Mining Metall. Pet. 2001, 109-114.

9. Duflou, J.R.; Lauwers, B.; Verbert, J.; Gelaude, F.; Tunckol, Y. Medical application of single point incremental forming: Cranial plate. In Virtual Modelling and Rapid Manufacturing: Advanced Research in Virtual and Rapid Prototyping, Proceedings of the 2nd International Conference on Advanced Research in Virtual and Rapid Prototyping, Leiria, Portugal, 28 September-1 October 2005; Francis: London, UK, 2005; p. 161.

10. Ambrogio, G.; Sgambitterra, E.; De Napoli, L.; Gagliardi, F.; Fragomeni, G.; Piccininni, A.; Gugleilmi, P.; Palumbo, G.; Sorgente, D.; La Barbera, L.; et al. Performances analysis of titanium prostheses manufactured by superplastic forming and incremental forming. Procedia Eng. 2017, 183, 168-173. [CrossRef]

11. Duflou, J.R.; Behera, A.K.; Vanhove, H.; Bertol, L.S. Manufacture of accurate titanium cranio-facial implants with high forming angle using single point incremental forming. Key Eng. Mater. 2013, 549, $223-230$. [CrossRef]

12. Ambrogio, G.; de Napoli, L.; Filice, L.; Gagliardi, F.; Muzzupappa, M. Application of Incremental Forming process for high customised medical product manufacturing. J. Mater. Process. Technol. 2005, 162, 156-162. [CrossRef]

13. Jeswiet, J.; Micari, F.; Hirt, G.; Bramley, A.; Duflou, J.; Allwood, J. Asymmetric single point incremental forming of sheet metal. CIRP Ann. 2005, 54, 88-114. [CrossRef]

14. Gupta, P.; Jeswiet, J. Effect of temperatures during forming in single point incremental forming. Int. J. Adv. Manuf. Technol. 2018, 95, 3693-3706. [CrossRef]

15. Azaouzi, M.; Lebaal, N. Tool path optimization for single point incremental sheet forming using response surface method. Simul. Model. Pract. Theory 2012, 24, 49-58. [CrossRef]

16. Durante, M.; Formisano, A.; Langella, A. Observations on the influence of tool-sheet contact conditions on an incremental forming process. J. Mater. Eng. Perform. 2011, 20, 941-946. [CrossRef]

17. Al-Ghamdi, K.A.; Hussain, G. Threshold tool-radius condition maximizing the formability in SPIF considering a variety of materials: Experimental and FE investigations. Int. J. Mach. Tools Manuf. 2015, 88, 82-94. [CrossRef]

18. Ambrogio, G.; Filice, L.; Manco, G.L. Warm incremental forming of magnesium alloy AZ31. Cirp Ann. Technol.Cirp Ann-Manuf Technol. 2008, 57, 257-260. [CrossRef]

19. Behera, A.K.; Gu, J.; Lauwers, B.; Duflou, J.R. Influence of material properties on accuracy response surfaces in single point incremental forming. Key Eng. Mater. 2012, 504, 919-924. [CrossRef]

20. Li, Z.; Lu, S.; Chen, P. Improvement of dimensional accuracy based on multistage single point incremental forming of a straight wall cylinder part. Int. J. Precis. Eng. Manuf. 2017, 18, 1281-1286. [CrossRef] 
21. Martins, P.A.F.; Kwiatkowski, L.; Franzen, V.; Tekkaya, A.E.; Kleiner, M. Single point incremental forming of polymers. CIRP Ann. 2009, 58, 229-232. [CrossRef]

22. Marques, T.A.; Silva, M.B.; Martins, P.A.F. On the potential of single point incremental forming of sheet polymer parts. Int. J. Adv. Manuf. Technol. 2012, 60, 75-86. [CrossRef]

23. Hirsch, J. Aluminium in innovative light-weight car design. Mater. Trans. 2011, 52, 818-824. [CrossRef]

24. Khan, S.; Hussain, G.; Ilyas, M.; Rashid, H.; Khan, M.I.; Khan, W.A. Appropriate heat treatment and incremental forming route to produce age-hardened components of Al-2219 alloy with minimized form error and high formability. J. Mater. Process. Technol. 2018, 256, 262-273. [CrossRef]

25. Mohammadi, A.; Vanhove, H.; van Bael, A.; Duflou, J.R. Enhanced formability of age-hardenable aluminium alloys by incremental forming of solution-treated blanks. Key Eng. Mater. 2013, 549, 164-171. [CrossRef]

26. Kassner, M.E.; Li, X.; McQueen, H.J. The effect of homogenization and precipitation treatments on the extrudability and ambient-temperature mechanical properties of aluminum alloy AA2024. Mater. Sci. Eng. A 1993, 169, 9-17. [CrossRef]

27. Totik, Y.; Gavgali, M. The effect of homogenization treatment on the hot workability between the surface and the center of AA 2014 ingots. Mater. Charact. 2002, 49, 261-268. [CrossRef]

28. Mohammadi, A.; Qin, L.; Vanhove, H.; Seefeldt, M.; van Bael, A.; Duflou, J.R. Single point incremental forming of an aged AL-cu-mg alloy: Influence of pre-heat treatment and warm forming. J. Mater. Eng. Perform. 2016, 25, 2478-2488. [CrossRef]

29. Wang, L.; Strangwood, M.; Balint, D.; Lin, J.; Dean, T.A. Formability and failure mechanisms of AA2024 under hot forming conditions. Mater. Sci. Eng. A 2011, 528, 2648-2656. [CrossRef]

30. Khalatbari, H.; Iqbal, A.; Shi, X.; Gao, L.; Hussain, G.; Hashemipour, M. High-speed incremental forming process: A trade-off between formability and time efficiency. Mater. Manuf. Process. 2015, 30, 1354-1363. [CrossRef]

31. Li, D.; Ghosh, A. Tensile deformation behavior of aluminum alloys at warm forming temperatures. Mater. Sci. Eng. A 2003, 352, 279-286. [CrossRef]

32. Otsu, M.; Ogawa, T.; Muranaka, T.; Yoshimura, H.; Matsumoto, R. Improvement of forming limit and accuracy in friction stir incremental forming with multistage forming. Procedia Eng. 2017, 207, 807-812. [CrossRef]

33. Lu, B.; Chen, J.; Ou, H.; Cao, J. Feature-based tool path generation approach for incremental sheet forming process. J. Mater. Process. Technol. 2013, 213, 1221-1233. [CrossRef]

34. Otsu, M.; Yasunaga, M.; Matsuda, M.; Takashima, K. Friction stir incremental forming of A2017 aluminum sheets. Procedia Eng. 2014, 81, 2318-2323. [CrossRef]

35. Duflou, J.R.; Callebaut, B.; Verbert, J.; de Baerdemaeker, H. Laser assisted incremental forming: Formability and accuracy improvement. CIRP Ann. 2007, 56, 273-276. [CrossRef]

36. Adams, D. Improvements on Single Point Incremental Forming through Electrically Assisted Forming, Contact Area Prediction and Tool Development. PhD Thesis, (Mechanical and Materials Engineering)-Queen's University, Kingston, Canada, 29 November 2013.

37. Otsu, M. Excellent Formability of Light Metals Sheets by Friction Stir Incremental Forming. Key Eng. Mater. 2016, 716, 3-10. [CrossRef]

38. Otsu, M.; Ichikawa, T.; Matsuda, M.; Takashima, K. Improvement of formability of magnesium alloy sheets by friction stir incremental forming. Steel Res. Int. Spec. Ed. 2011, 537-541.

39. Otsu, M. Friction stir incremental forming of aluminum alloy sheets. Proc. Met. 2010, 2010, 942-945.

40. Ham, M.; Jeswiet, J. Single point incremental forming and the forming criteria for AA3003. CIRP Ann. 2006, 55, 241-244. [CrossRef]

41. Buffa, G.; Campanella, D.; Fratini, L. On the improvement of material formability in SPIF operation through tool stirring action. Int. J. Adv. Manuf. Technol. 2013, 66, 1343-1351. [CrossRef]

42. Buffa, G.; Campanella, D.; Mirabile, R.; Fratini, L. Improving formability in SPIF processes through high speed rotating tool: Experimental and numerical analysis. Key Eng. Mater. 2013, 549, 156-163. [CrossRef]

(C) 2020 by the authors. Licensee MDPI, Basel, Switzerland. This article is an open access article distributed under the terms and conditions of the Creative Commons Attribution (CC BY) license (http://creativecommons.org/licenses/by/4.0/). 